\title{
Ações educativas de enfrentamento ao Aedes Aegypti: revisão integrativa
}

\author{
Education-based Aedes Aegypti control actions: \\ an integrative review
}

Ítala Keane Rodrigues Dias (https://orcid.org/0000-0003-3027-825X) ${ }^{1}$

Rosa Maria Grangeiro Martins (https://orcid.org/0000-0002-2516-0719) ${ }^{1}$

Cicera Luciana da Silva Sobreira (https://orcid.org/0000-0003-2380-9606) ${ }^{1}$

Rhavena Maria Gomes Sousa Rocha (https://orcid.org/0000-0001-6341-4735) ${ }^{1}$

Maria do Socorro Vieira Lopes (https://orcid.org/0000-0003-1335-5487) ${ }^{1}$

\footnotetext{
${ }^{1}$ Universidade Regional do Cariri. R. Cel. Antônio Luíz 1161, Pimenta. 63105-010 Crato CE Brasil. itala_keany@hotmail.com

\begin{abstract}
The aim of this study was to provide a synthesis of published studies investigating education-based arbovirus control strategies. The data were collected from the LILACS, BDENF and MEDLINE databases using the descriptors "Health Education" and "Aedes", together with the Boolean operator "AND". The searches retrieved 242 studies, 14 of which were included in the review after applying the inclusion and exclusion criteria. The data were analyzed using a qualitative approach, resulting in the identification of four categories: vector control actions based on community capacity building; social mobilization for arbovirus control; education-based vector control combined with biological control; and integrated arbovirus control actions. The findings show that health education is an essential element of arbovirus control and should be implemented in conjunction with other vector control strategies.

Key words Vector Control, Aedes, Public Health Surveillance, Prevention \& Control, Health Education
\end{abstract}

Resumo Objetivou sintetizar os estudos, publicados na literatura cientifica, que abordem estratégias de enfrentamento às arboviroses mediante ações educativas. Os dados foram coletados nas bases de dados: LILACS, BDENF e MEDLINE utilizando os descritores "Educação em Saúde" e "Aedes" empregando o operador booleano "AND". Foram encontrados 242 estudos, dos quais após aplicação dos critérios de inclusão e exclusão, 14 foram incluídos na revisão. Os dados foram analisados utilizando a abordagem qualitativa. Foram identificadas quatro categorias: ações de enfrentamento vetorial mediante capacitação da comunidade; mobilização social em torno do combate às arboviroses; combate vetorial a partir de ações educativas associadas ao uso de controle biológico; ações integradas de enfrentamento às arboviroses. Infere-se que a educação em saúde é um elemento indispensável para o enfrentamento às arboviroses que deverá ser implementada de forma conjunta e articuladas às demais estratégia de combate vetorial.

Palavras-chave Controle de Vetores, Aedes, Vigilância em Saúde Pública, Prevenção \& Controle, Educação em Saúde 


\section{Introdução}

As características climáticas do Brasil associadas à extensão territorial, vegetação, condições de habitação e saneamento básico dos brasileiros contribuem para incidências de epidemias de arboviroses transmitidas pelo mosquito Aedes aegypti ${ }^{1}$. Embora algumas arboviroses o paciente apresente recuperação completa após a fase aguda, há casos em que os sintomas perduram semanas a meses, podendo o quadro evoluir com complicações hemorrágicas ou neurológicas, algumas delas irreversíveis ${ }^{2,3}$. A persistência de arboviroses como a Dengue e a eminência dos surtos de doenças emergentes como Chikungunya e Zika revelam as fragilidades sociais e políticas do país e evidenciam a necessidade de estratégias efetivas e eficazes de enfrentamento vetorial ${ }^{1}$. O fato da Organização Mundial da Saúde (OMS) em 2016 emitir um alerta declarando o Zika Vírus (ZIKV) como um problema de saúde pública, após a associação deste vírus aos casos de microcefalia, sucinta a magnitude da gravidade das arboviroses, as quais além de sobrecarregar os serviços de saúde perpetuam o ciclo de pobreza no país ${ }^{3,4}$.

$\mathrm{Na}$ ausência de vacinas e tratamentos específicos, larvicidas e inseticidas têm sido utilizados com frequência, sobretudo em períodos endêmicos, contudo estes métodos não demonstraram controle vetorial ${ }^{5,6}$. Essas substâncias químicas propiciam resistência ao mosquito e contribuem para aumentar a magnitude de futuras epidemias $^{7}$. Elas apresentam elevado valor econômico, inicialmente, até reduzem a quantidade de mosquitos, contudo, na medida em que a resistência evolui a quantidade de vetores aumenta ${ }^{6-8}$.

Outras estratégias têm sido aplicadas e avaliadas, como por exemplo a infecção do Aedes aegypti com a bactéria Bolbachia. A infecção proporciona ao mosquito uma alteração imunológica, capaz de interromper a cadeia de transmissão de doenças, com a Dengue9.

Em 2002 o governo instituiu o Programa Nacional de Controle da Dengue (PNCD), que propõe mudanças na forma de controlar as arboviroses, enfatizando a importância da adesão e mobilização social, bem como incentivar a atuação das pessoas como responsáveis pelo controle de potenciais criadouros. O programa foi um marco para o enfrentamento às arboviroses no Brasil ${ }^{10}$.

A educação em saúde passa a assumir posição de destaque, sendo percebida como uma das estratégias de prevenção essencial. É a partir da educação que é possível construir os fundamen- tos de uma sociedade sustentável, potencializando mudanças culturais e sociais que favoreçam a melhoria socioambiental, competências necessárias para o fortalecimento dos cuidados individuais e coletivos com o meio ambiente, indispensáveis para manutenção de ambientes isentos dos riscos de reprodução do mosquito ${ }^{8,11}$.

Em uma revisão integrativa realizada no ano de 2013 com o objetivo de investigar quais estratégias de educação em saúde estão sendo utilizadas para controle/combate das arboviroses no Brasil, verificou-se que há um quantitativo baixo de publicações brasileiras que associam o combate destas doenças à educação em saúde. $\mathrm{Na}$ mesma pesquisa se evidenciou a necessidade de mudanças nas estratégias educativas, tornando claro que formas tradicionais de educação não têm sido suficientes para produzir respostas positivas na população para o controle de vetores ${ }^{12}$.

Tendo em vista os investimentos do governo em políticas públicas de mobilização social em torno do combate às arboviroses e as lacunas de estudos publicados no âmbito brasileiro que abordem estratégias de enfrentamento mediante ações educativas, este estudo foi desenvolvido a partir das seguintes perguntas norteadoras: Quais estratégias educativas de enfrentamento às arboviroses têm sido realizadas em âmbito mundial, publicados na literatura cientifica? Quais foram os resultados obtidos nos respectivos estudos?

As respostas destes questionamentos constituirão para que esta pesquisa represente um referencial teórico que subsidiará o planejamento dos programas e políticas públicas em torno do enfrentamento às doenças vetoriais, com ênfase nas medidas educativas para redução das principais doenças transmitidas pelo mosquito Aedes. Portanto, o objetivo desta pesquisa consistiu em sintetizar os estudos, publicados na literatura cientifica, que incluíram estratégias de enfrentamento às arboviroses a partir de ações educativas.

\section{Método}

Para alcançar o objetivo do estudo, realizou-se uma revisão integrativa da literatura, a qual consiste em um método de pesquisa que permite a busca, a avaliação crítica e a síntese das evidências disponíveis do tema investigado, sendo o seu produto final o estado atual do conhecimento do tema investigado. Para isso, foram seguidas seis etapas: 1) identificação da questão de pesquisa; 2) busca na literatura; 3) categorização dos estudos; 4) avaliação dos estudos incluídos na revi- 
são; 5) interpretação dos resultados; 6) apresentação da revisão ${ }^{13}$.

A busca na literatura foi realizada a partir das seguintes questões de pesquisa: Quais estratégias educativas de enfrentamento às arboviroses têm sido realizadas em âmbito mundial, publicadas na literatura cientifica? Quais foram os resultados obtidos nos respectivos estudos?

A seleção dos estudos foi realizada no ano de 2016 mediante busca online das publicações científicas que respondessem as questões da pesquisa, nas seguintes bases de dados: Literatura Latino Americana e do Caribe em Ciências da Saúde (LILACS), Base de dados da Enfermagem (BDENF) e Medical Literature Analysis and Retrieval System Online (MEDLINE). Para a busca, realizou-se o cruzamento em todas as fontes supracitadas dos Descritores da Ciência da Saúde (DeCS) no idioma português "Educação em Saúde" e "Aedes" empregando o operador booleano "AND".

Durante a busca em todas as fontes de dados, foram empregados os filtros: texto disponível completo, estudos publicados entre os anos 2010 e 2016. Justifica-se a aplicação do primeiro filtro a ausência de financiamento para o desenvolvimento da pesquisa e o segundo por considerar atualizados os estudos publicados nesses períodos. Foram incluídos na revisão estudos em idiomas português, inglês e espanhol.

Foram excluídos estudos no formato de cartas e editoriais, devido ao rigor científico destas publicações, estudos repetidos e aqueles não condizentes com o objetivo da revisão, conforme apresentado na Figura 1 na etapa "Elegibilidade".

A utilização dos descritores resultou em 242 achados. A seleção dos achados foi realizada mediante a aplicação dos filtros aplicados seguida da leitura dos títulos, resumos e dos textos na íntegra, a fim de atender aos critérios de inclusão e exclusão estabelecidos para a pesquisa (Figura 1).

Após aplicação dos filtros e critérios de inclusão e exclusão, se obteve um número de 59 estudos, distribuídos nas três fontes de dados. Foi realizada a leitura na íntegra do texto completo dos 59 estudos, para identificação do conteúdo abordado e excluídos aqueles que não atendiam os objetivos da revisão, resultando em 14 estudos incluídos na revisão (Figura 1).

Após seleção dos estudos incluídos na revisão, os dados foram agrupados em um formulário e organizados em planilha do Microsorft Excel, contendo itens referentes às características dos estudos (autores, título do artigo, periódico, ano da publicação, país, período da realização do estudo, idioma, tipo de estudo, participantes, in- tervenções de combate e controle do mosquito, resultados e conclusões).

Os dados obtidos foram analisados utilizando a abordagem qualitativa, a partir da leitura minuciosa dos estudos incluídos na revisão, para identificação das categorias temáticas. Após a leitura foram identificadas quatro categorias. Para melhor compreensão dos resultados, os dados obtidos foram resumidos e compilados em forma de quadros.

\section{Resultados}

Os quatorze estudos incluídos na revisão integrativa são todos artigos científicos publicados em periódicos, a maioria no idioma inglês $64,2 \%$ $(\mathrm{N}=9)$, seguido de espanhol $21,4 \%(\mathrm{~N}=3)$ e português $14,2 \%(\mathrm{~N}=2)$. O delineamento metodológico de $64,2 \%$ correspondeu à pesquisa experimental $(\mathrm{N}=9), 28,5 \%$ quase experimental $(\mathrm{N}=3)$ e $7,1 \%$ relato de experiência $(\mathrm{N}=1)$. As pesquisas foram realizadas em diferentes continentes, sobretudo na América Latina, sendo o Brasil o país com o maior número de estudos $(\mathrm{N}=3)$.

A análise de conteúdo dos estudos permitiu identificar quatro categorias. A primeira "Ações de enfrentamento vetorial mediante capacitação da comunidade", composta por seis estudos, apresentados no Quadro 1. Nestes estudos, escolas e o domicílio foram os espaços em que ocorreram as intervenções educativas. Os alvos das ações abrangeram professores, adultos, crianças, alunos, líderes comunitários, zeladores de escolas e outros profissionais. Em relação aos métodos empregados, foram realizadas capacitações com o auxílio de folhetos, conferências, Workshops, Slides, Sites e conversas.

A segunda categoria "Mobilização social em torno do combate às arboviroses" foi composta por seis estudos, apresentados no Quadro 2. Nesta categoria os estudos desenvolveram intervenções educativas associadas à mobilização social coletiva. As ações desenvolvidas abrangeram bairros, comunidades e grupos. Além da distribuição de materiais educativos em torno da temática, foram realizadas campanhas de limpeza mediante coleta de lixos, mutirões, gincanas e recolhimento de material reciclável.

A terceira categoria "Combate vetorial a partir de ações educativas associadas ao uso de controle biológico" foi composta por apenas um estudo, em que se utilizou predadores naturais do vetor junto de ações educativas para o enfretamento ao Aedes (Quadro 3). 


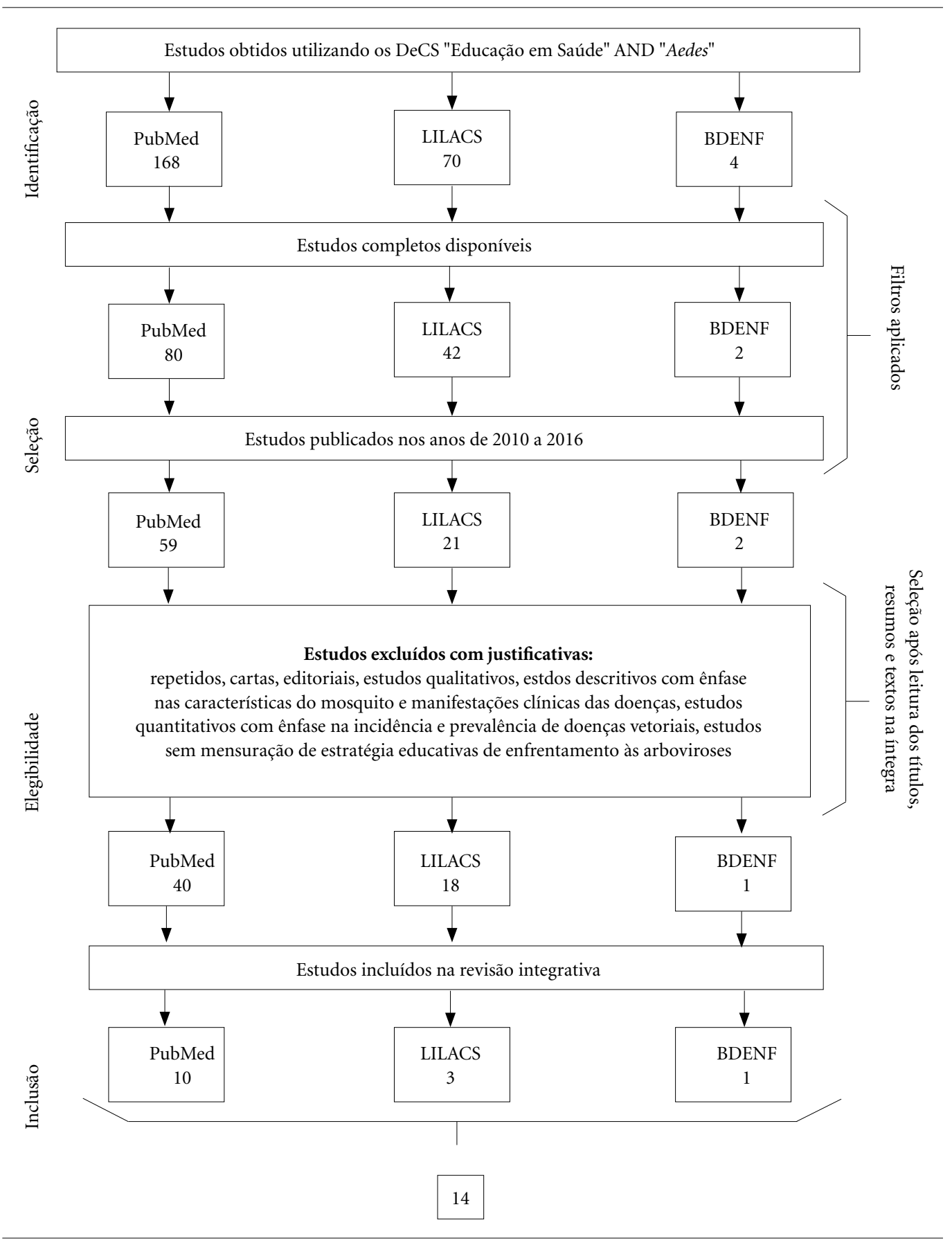

Figura 1. Descrição do fluxo de seleção dos estudos da revisão integrativa.

Fonte: Adaptado de Galvão et al. ${ }^{14}$.

A quarta categoria "Ações integradas de enfrentamento às arboviroses" foi composta por apenas um estudo, o qual apresenta a realização de ações educativas integradas à implementação de políticas públicas. As intervenções que obtive- ram resultados satisfatórios consistiram naquelas em que houve o emprego de múltiplas estratégias de enfrentamento às arboviroses, com ênfase na mobilização coletiva, emprego de métodos ativos e envolvimento da gestão pública (Quadro 4). 
Quadro 1. Síntese dos estudos incluídos na Categoria 1 "Ações de enfrentamento vetorial mediante capacitação da comunidade”.

\begin{tabular}{|c|c|c|c|}
\hline $\begin{array}{c}\text { Autores/ } \\
\text { País/ } \\
\text { Ano de } \\
\text { publicação }\end{array}$ & $\begin{array}{c}\text { Delineamento } \\
\text { do estudo/ } \\
\text { Idioma }\end{array}$ & Intervenções dos respectivos estudos & Resultados obtidos \\
\hline $\begin{array}{l}\text { Bartlett- } \\
\text { Healy et } \\
\text { al. }{ }^{15 /} \\
\text { Estados } \\
\text { Unidos/ } \\
2011\end{array}$ & $\begin{array}{l}\text { Experimental/ } \\
\text { Inglês }\end{array}$ & $\begin{array}{l}\text { O estudo abrangeu três comunidades. Em uma os professores } \\
\text { do ensino fundamental foram capacitados e receberam } \\
\text { materiais para realizar educação em saúde; todas as crianças que } \\
\text { participaram receberam um “take-home ovitra" para coletar ovos } \\
\text { do mosquito e instruções de como contar ovos e como fazer } \\
\text { upload dos dados em um site da internet contendo diversos jogos } \\
\text { informáticos. Na segunda comunidade a atividade foi direcionada } \\
\text { aos adultos, os quais receberam folhetos educativos ao longo da } \\
\text { primavera e verão. Na terceira não houve nenhuma intervenção }\end{array}$ & $\begin{array}{l}\text { Não houve diferenças } \\
\text { significativas na redução dos } \\
\text { focos do mosquito em relação } \\
\text { às comunidades que realizaram } \\
\text { as ações educativas e aqueles } \\
\text { que não recebem. O grupo em } \\
\text { que se utilizou site apresentou } \\
\text { uma diferença significativa no } \\
\text { comportamento }\end{array}$ \\
\hline $\begin{array}{l}\text { Cáceres- } \\
\text { Manrique } \\
\text { et al. }{ }^{16 /} \\
\text { Colômbia/ } \\
2010\end{array}$ & $\begin{array}{l}\text { Experimental/ } \\
\text { Espanhol }\end{array}$ & $\begin{array}{l}\text { O estudo foi realizado em quatro distritos. Em dois houve } \\
\text { intervenção enquanto dois eram controles. A intervenção } \\
\text { consistiu em visitas domiciliares para investigação dos } \\
\text { conhecimentos, práticas e apropriação da população. } \\
\text { Posteriormente se realizou uma estratégia educativa direcionada } \\
\text { aos líderes comunitários para capacitá-los para conduzir ações de } \\
\text { vigilância, prevenção e controle vetoriais }\end{array}$ & $\begin{array}{l}\text { A intervenção foi eficaz. Houve } \\
\text { uma redução da taxa larval de } \\
20 \% \text { e prevalência da Dengue de } \\
4,5 \% \text {, nos locais de intervenção. } \\
\text { Nos controles a taxa larval foi } \\
\text { de } 15,9 \% \text { e a prevalência da } \\
\text { Dengue foi de } 6,7 \%\end{array}$ \\
\hline $\begin{array}{l}\text { Contreras } \\
\text { et al. } .^{17} / \\
\text { Cuba/ } \\
2012\end{array}$ & $\begin{array}{l}\text { Quase } \\
\text { experimental/ } \\
\text { Espanhol }\end{array}$ & $\begin{array}{l}\text { O estudo avaliou o impacto de uma intervenção educativa } \\
\text { abordando Dengue, direcionada aos profissionais que atuam no } \\
\text { combate vetorial de três comunidades. A estratégia educativa } \\
\text { consistiu em conferências, seguida de workshops da temática } \\
\text { e entrega de uma brochura aos participantes. O grau de } \\
\text { conhecimentos foi medido antes e depois da intervenção }\end{array}$ & $\begin{array}{l}\text { A estratégia educacional foi } \\
\text { eficaz por elevar o nível de } \\
\text { conhecimento dos profissionais, } \\
\text { nas questões referente às ações } \\
\text { de controle vetoriais }\end{array}$ \\
\hline $\begin{array}{l}\text { Hernández- } \\
\text { Suárez e } \\
\text { Mendoza- } \\
\text { Cano }^{18} / \\
\text { México/ } \\
2016\end{array}$ & $\begin{array}{l}\text { Quase } \\
\text { experimental/ } \\
\text { Inglês }\end{array}$ & $\begin{array}{l}\text { A estratégia utilizada no estudo consistiu em uma campanha } \\
\text { para formação de zeladores de escolas primárias, antes de iniciar } \\
\text { o ano letivo, para localizar e evitar os locais de reprodução dos } \\
\text { mosquitos. A estratégia durou em média } 2,5 \text { horas. Durante o } \\
\text { treinamento foi usando slides, seguido de uma visita aos lugares } \\
\text { típicos dentro de escolas onde o mosquito pode se reproduzir e } \\
\text { viver }\end{array}$ & $\begin{array}{l}\text { Foi obtida uma redução de } \\
45 \% \text { na incidência de Dengue } \\
\text { em relação ao ano anterior, } \\
\text { nas escolas em que se realizou } \\
\text { a formação dos zeladores das } \\
\text { escolas }\end{array}$ \\
\hline $\begin{array}{l}\text { Silva et al. }{ }^{19} / \\
\text { Brasil/ } \\
2013\end{array}$ & $\begin{array}{l}\text { Quase } \\
\text { experimental/ } \\
\text { Português }\end{array}$ & $\begin{array}{l}\text { O estudo foi realizado em escolas públicas e residências, em } \\
\text { que foram feitas visitas domiciliares pelos pesquisadores junto } \\
\text { aos agentes de endemias para observar a situação dos quintais e } \\
\text { preencher um checklist. A partir disso, os pesquisadores puderam } \\
\text { definir ações educativas para serem realizadas nas escolas que } \\
\text { pudessem ampliar os conhecimentos dos estudantes acerca da } \\
\text { prevenção e controle vetorial, fundamentada nos pressupostos da } \\
\text { aprendizagem significativa. A ação educativa incluiu os seguintes } \\
\text { componentes: aula expositiva, ministrada pelos pesquisadores; } \\
\text { distribuição de um recurso preventivo “Evidengue }{ }^{\circledR} \text { ” um folheto } \\
\text { informativo. Após a ação educativa na escola, foram realizadas } \\
\text { outras duas visitas das residências para verificar a situação das } \\
\text { residências e adesão do Evidengue }{ }^{\circledR}, \text { preenchendo novamente um } \\
\text { checklist }\end{array}$ & $\begin{array}{l}\text { A atividade educativa } \\
\text { demonstrou um potencial } \\
\text { para o controle do vetor. } \\
\text { Na primeira visita } 89,3 \% \\
\text { das casas havia presença de } \\
\text { algum recipiente propício à } \\
\text { reprodução do vetor da Dengue. } \\
\text { Após o desenvolvimento das } \\
\text { ações educativas, na segunda } \\
\text { e terceira visitas, o número de } \\
\text { focos diminuiu para (70,0\%) e } \\
(68,0 \%) \text { respectivamente }\end{array}$ \\
\hline $\begin{array}{l}\text { Torres et } \\
\text { al. }^{20} / \\
\text { México/ } \\
2014\end{array}$ & $\begin{array}{l}\text { Quase } \\
\text { experimental/ } \\
\text { Espanhol }\end{array}$ & $\begin{array}{l}\text { O estudo avaliou uma intervenção educativa com uma população } \\
\text { de } 3.124 \text { alunos, dos quais participaram da intervenção } 1.562 \text {, os } \\
\text { demais constituíram o grupo controle. Aplicou-se um inquérito } \\
\text { sobre conhecimentos, atitudes e práticas antes e depois da } \\
\text { estratégia educativa. A estratégia consistiu em uma conversa de } \\
\text { cerca de } 60 \text { minutos, com ênfase na participação dos alunos no } \\
\text { autocuidado e prevenção e controle de vetores. Foi apresentado o } \\
\text { Aedes in vivo, seguido de um passeio nos pátios das escolas para } \\
\text { identificar e registrar os tipos de recipientes capazes de servir de } \\
\text { focos de reprodução do mosquito }\end{array}$ & $\begin{array}{l}\text { Os participantes da intervenção } \\
\text { obtiveram aumento significativo } \\
\text { de conhecimentos, atitudes } \\
\text { e práticas, com diferença } \\
\text { estatística significativa em } \\
\text { todos os itens avaliados, em } \\
\text { comparação ao grupo controle }\end{array}$ \\
\hline
\end{tabular}


Quadro 2. Síntese dos estudos incluídos na Categoria 2 "Mobilização social em torno do combate às arboviroses".

\begin{tabular}{|c|c|c|c|}
\hline $\begin{array}{c}\text { Autores/ } \\
\text { País/ } \\
\text { Ano de } \\
\text { publicação }\end{array}$ & $\begin{array}{l}\text { Delineamento } \\
\text { do estudo/ } \\
\text { Idioma }\end{array}$ & Intervenções dos respectivos estudos & Resultados obtidos \\
\hline $\begin{array}{l}\text { Arunachalam } \\
\text { et al. }{ }^{21} / \\
\text { Índia/ } \\
2012\end{array}$ & $\begin{array}{l}\text { Experimental/ } \\
\text { Inglês }\end{array}$ & $\begin{array}{l}\text { O estudo foi desenvolvido em dois conjuntos de bairros, } \\
\text { cada um contendo } 1.000 \text { casas. Em um foi realizada uma } \\
\text { abordagem de gestão ambiental, mapeou-se um programa } \\
\text { de controle do mosquito envolvendo diretamente a } \\
\text { comunidade mediante mobilização de grupos de autoajuda } \\
\text { e de escolares para prevenção da Dengue, distribuição de } \\
\text { material informativo na comunidade, campanhas de limpezas } \\
\text { nos bairros, eliminação de resíduos e reciclagem. O outro } \\
\text { conjunto de bairro recebeu os serviços governamentais de } \\
\text { rotina }\end{array}$ & $\begin{array}{l}\text { A infestação vetorial foi } \\
\text { significativamente menor } \\
\text { nos bairros da intervenção. } \\
\text { O índice de pupas por pessoa } \\
\text { foi reduzido para } 0,004 \text { de } \\
1.075 \text { e os índices vetoriais } \\
\text { por casa foi reduzido de } \\
4,2 \% \text { para } 1,05 \%\end{array}$ \\
\hline $\begin{array}{l}\text { Caprara et } \\
\text { al. }^{22 /} \\
\text { Brasil/ } \\
2015\end{array}$ & $\begin{array}{l}\text { Experimental/ } \\
\text { Inglês }\end{array}$ & $\begin{array}{l}\text { O estudo analisou uma intervenção para redução do } A \text {. } \\
\text { aegypti comparando dez grupos de intervenção com dez } \\
\text { controles. Nestes últimos foram realizadas atividades } \\
\text { rotineiras de controle do vetor, enquanto no primeiro se } \\
\text { identificou as pessoas "chaves" na comunidade os quais foram } \\
\text { capacitados para mobilizar a participação da comunidade } \\
\text { no programa de gestão ambiental (oficinas, campanhas de } \\
\text { limpeza, eliminação de lixos, mobilização de escolares e } \\
\text { grupos da comunidade, distribuição de material informativo) }\end{array}$ & $\begin{array}{l}\text { Antes e após a intervenção } \\
\text { foram identificadas fortes } \\
\text { diferenças entre as áreas de } \\
\text { intervenção e de controles }\end{array}$ \\
\hline $\begin{array}{l}\text { Costa et al. } .^{23} / \\
\text { Brasil/ } \\
2012\end{array}$ & $\begin{array}{l}\text { Relato de } \\
\text { experiência/ } \\
\text { Português }\end{array}$ & $\begin{array}{l}\text { O estudo descreve a implantação do projeto intitulado } \\
\text { "Amigos do bairro contra Dengue". As atividades do projeto } \\
\text { consistiram na realização de vinte e três mutirões, dez } \\
\text { gincanas em escolas para recolhimento de material reciclável. } \\
\text { Foram entregues certificados de participação e apresentada } \\
\text { às atividades desenvolvidas em um evento na comunidade } \\
\text { com exposição de material reciclado, apresentações teatrais, } \\
\text { fantoches e grupos de danças populares }\end{array}$ & $\begin{array}{l}\text { Foram eliminados meca- } \\
\text { nicamente } 5.145 \text { criadouros } \\
\text { do mosquito, distribuídos } \\
\text { em } 3.258 \text { imóveis, com uma } \\
\text { média de } 1,58 \text { criadouros } \\
\text { por imóvel }\end{array}$ \\
\hline $\begin{array}{l}\text { Healy et al. }{ }^{24} / \\
\text { Estados } \\
\text { Unidos/ } \\
2014\end{array}$ & $\begin{array}{l}\text { Experimental/ } \\
\text { Inglês }\end{array}$ & $\begin{array}{l}\text { O estudo avaliou um programa de redução de focos dos } \\
\text { mosquitos em que voluntários da comunidade foram } \\
\text { capacitados para educar seus pares nos domicílios para } \\
\text { prevenção e controle do mosquito. A educação ativa foi feita } \\
\text { por equipes, as quais realizavam a vistoria nos quintais junto } \\
\text { aos moradores, apontando os habitats atuais e potenciais. } \\
\text { Além disso, se realizou vários eventos educacionais na } \\
\text { comunidade utilizado impressos e fazendo a coletas de lixos } \\
\text { nas ruas }\end{array}$ & $\begin{array}{l}\text { Houve redução significativa } \\
\text { dos habitats do mosquito } \\
\text { nos locais em que houve } \\
\text { participação ativa da } \\
\text { comunidade. Nas áreas de } \\
\text { intervenção houve aumento } \\
\text { de } 22,6 \% \text { dos habitats em } \\
\text { comparação a } 32,3 \% \text { nas } \\
\text { áreas sem intervenção }\end{array}$ \\
\hline $\begin{array}{l}\text { Kittayapong } \\
\text { et al. }{ }^{25 /} \\
\text { Tailândia/ } \\
2012\end{array}$ & $\begin{array}{l}\text { Experimental/ } \\
\text { Inglês }\end{array}$ & $\begin{array}{l}\text { O estudo foi realizado em três comunidades em que se } \\
\text { escolheu aleatoriamente o grupo de intervenção e o controle. } \\
\text { Nos grupos de intervenção os líderes comunitários e as } \\
\text { autoridades governamentais foram identificados e treinados } \\
\text { para conduzir atividades de controle do mosquito em suas } \\
\text { próprias comunidades através da gestão ambiental. Estes } \\
\text { voluntários treinados realizaram educação em saúde e } \\
\text { controle vetorial durante as visitas domiciliares, gestão do } \\
\text { espaço público e gestão de resíduos sólidos }\end{array}$ & $\begin{array}{l}\text { Na comunidade da } \\
\text { intervenção a comunidade } \\
\text { demonstrou redução } \\
\text { significativa dos índices } \\
\text { de pupas por pessoa } \\
\text { durante levantamentos } \\
\text { entomológicos que foram } \\
\text { conduzidos em intervalos de } \\
\text { dois meses }\end{array}$ \\
\hline $\begin{array}{l}\text { Mitchell- } \\
\text { Foster et al. }{ }^{26 /} \\
\text { Canadá/ } \\
2015\end{array}$ & $\begin{array}{l}\text { Experimental/ } \\
\text { Inglês }\end{array}$ & $\begin{array}{l}\text { Este estudo avaliou uma Estratégia de Intervenção Integrada } \\
\text { para prevenção da dengue em vinte bairros, em que dez deles } \\
\text { se implementou um programa educativo de combate à dengue } \\
\text { "Pátio limpo" e um programa de "contêineres seguros", } \\
\text { enquanto dez bairros foram grupos controles. Foi dada } \\
\text { especial atenção à mobilização social e ao empoderamento } \\
\text { dos participantes da Estratégia de Intervenção Integrada }\end{array}$ & $\begin{array}{l}\text { A Estratégia de Intervenção } \\
\text { Integrada foi bem sucedida. } \\
\text { Houve uma redução índice } \\
\text { de Pupa por pessoa nas } \\
\text { comunidades de intervenção } \\
\text { em comparação ao grupo } \\
\text { controle }\end{array}$ \\
\hline
\end{tabular}


Quadro 3. Síntese do estudo incluído na Categoria 3 "Combate vetorial a partir de ações educativas associadas ao uso de controle biológico".

\begin{tabular}{|c|c|c|c|}
\hline $\begin{array}{c}\text { Autores/Pais/ } \\
\text { Ano de } \\
\text { publicação }\end{array}$ & $\begin{array}{c}\text { Delineamento } \\
\text { do estudo/ } \\
\text { Idioma }\end{array}$ & Estratégias utilizadas nos respectivos estudos & Resultados obtidos \\
\hline $\begin{array}{l}\text { Ghosh et } \\
\text { al. }{ }^{27 /} \\
\text { Índia/ } \\
2011\end{array}$ & $\begin{array}{l}\text { Experimental/ } \\
\text { Inglês }\end{array}$ & $\begin{array}{l}\text { O estudo foi realizado em três comunidades } \\
\text { em que se avaliou a eficácia de campanhas } \\
\text { educativas e a utilização de dois tipos de } \\
\text { peixes (Poecilia reticulata e Gambusia Affinis), } \\
\text { depositados em tanques de cimento para } \\
\text { controle larval. Em uma comunidade foi } \\
\text { depositada em tanques nas residências a Poecilia } \\
\text { reticulata e realizada atividades educativas } \\
\text { abordando os cuidados para a manutenção } \\
\text { dos peixes, modo de transmissão e tratamento } \\
\text { das doenças transmitidas pelo mosquito. Em } \\
\text { outra comunidade foi realizada a mesma ação } \\
\text { educativa, porém utilizando o peixe Gambusia } \\
\text { Affinis. Enquanto na terceira comunidade o peixe } \\
\text { Poecilia reticulata foi distribuído nas residências } \\
\text { e não houve nenhuma campanha educativa }\end{array}$ & $\begin{array}{l}\text { O peixe Poecilia reticulata } \\
\text { associado à intervenção } \\
\text { educativa foi mais eficaz, } \\
\text { reduzindo os casos de } \\
\text { Chikungunya a } 99,87 \% \text {. } \\
\text { Na comunidade em que se } \\
\text { utilizou Gambusia Affinis } \\
\text { e campanhas educativas } \\
\text { a redução foi de } 68,51 \% \text {. } \\
\text { Enquanto onde se utilizou } \\
\text { apenas Poecilia reticulata a } \\
\text { redução foi de } 65,48 \%\end{array}$ \\
\hline
\end{tabular}

Fonte: Autoras.

Quadro 4. Síntese do estudo incluído na Categoria 4 “Ações integradas de enfrentamento às arboviroses”.

\begin{tabular}{|c|c|c|c|}
\hline $\begin{array}{c}\text { Autores/Pais/ } \\
\text { Ano de } \\
\text { publicação }\end{array}$ & $\begin{array}{c}\text { Delineamento } \\
\text { do estudo/ } \\
\text { Idioma }\end{array}$ & Estratégias utilizadas nos respectivos estudos & Resultados obtidos \\
\hline $\begin{array}{l}\text { Nam et al. }{ }^{28} / \\
\text { Vietnã/ } \\
2012\end{array}$ & $\begin{array}{l}\text { Experimental/ } \\
\text { Inglês }\end{array}$ & $\begin{array}{l}\text { O estudo foi realizado em quatorse } \\
\text { comunidades, das quais doze participaram da } \\
\text { intervenção. Na comunidade de intervenção as } \\
\text { ações foram implementadas durante sete anos. } \\
\text { Foi implantado um sistema de abastecimento } \\
\text { de água e saneamento, representantes e } \\
\text { lideres de diversos setores da sociedade civil } \\
\text { foram treinados em oficinas e avaliados para } \\
\text { implementação das estratégias propostas. Ao } \\
\text { final da capacitação os voluntários receberam } \\
\text { kits, livros para registro de intervenções, } \\
\text { listas das casas que cada colaborador iria } \\
\text { se responabilizar e um cronograma de } \\
\text { atividades. Professores de escolas primárias } \\
\text { e escolas secundárias também foram alvos de } \\
\text { treinamento }\end{array}$ & $\begin{array}{l}\text { O projeto apresentou } \\
\text { alta eficiência, eficácia e } \\
\text { sustentabilidade. A média } \\
\pm \text { de adultas femeas do } A \text {. } \\
\text { Aegypti foi reduzido de } 0,93 \\
\pm 0,62 \text { a } 0,06 \pm 0,09, \text { e o } A \text {. } \\
\text { Aegypti imaturo apresentou } \\
\text { redução média de } 98,8 \% \text {. Ao } \\
\text { final do projeto nenhuma } \\
\text { forma adulta foi encontrada } \\
\text { em seis das comunidades }\end{array}$ \\
\hline
\end{tabular}

Fonte: Autoras.

As intervenções que obtiveram resultados satisfatórios consistiram naquelas em que houve o emprego de múltiplas estratégias de enfrentamento às arboviroses, com ênfase na mobilização coletiva, emprego de métodos ativos e envolvimento da gestão pública.

\section{Discussões}

O idioma inglês prevaleceu nos estudos incluídos nesta pesquisa, este achado relaciona-se à hegemonia desta língua. Encontrar pesquisas realizadas em diferentes países que abordem intervenções de enfrentamento às doenças transmitidas 
pelo mosquito Aedes, demonstra o interesse dos países de diferentes continentes na busca de aperfeiçoar e desenvolver estratégias alternativas que possam contribuir para prevenção dos agravos à saúde decorrentes das arboviroses.

A quantidade de estudos realizados no Brasil decorre de o país possuir condições ambientais e estruturais que contribuem para a persistência dos problemas de saúde pública ocasionados pelo Aedes, demandando o desenvolvido frequente de pesquisas na área ${ }^{1}$ Embora o Brasil tenha apresentado um número maior de estudos, observa-se que o quantitativo obtido ainda é considerado pequeno, tendo em vista ser um país endêmico para estas doenças. Este achado está de acordo com outra revisão integrativa, realiza$\mathrm{da}$ anteriormente, em que foi possível encontrar apenas cinco publicações abordando a utilização de ações educativas para controle das arboviroses no Brasil ${ }^{12}$.

Foram incluídos na Categoria 1 apenas estudos que utilizaram estratégias educativas que tinham o propósito de aumentar os conhecimentos da população em torno dos aspectos das arboviroses, com o objetivo de sensibilizar os participantes das intervenções a serem capazes de gerenciar os ambientes que habitam, tornando-os isentos dos vetores que ofereçam riscos à saúde.

As estratégias utilizadas na Categoria 1 se tornam eficazes na medida em que apropriam a população em relação aos aspectos importantes da prevenção das doenças, como exemplo a abordagem do agente transmissor, os possíveis locais de reprodução do mosquito e das diversas formas de erradicá-lo. É indispensável abordar o impacto do vetor nas comunidades e as medidas simples de combatê-lo, para que os cidadãos tenham consciência da importância de aderir às estratégias de enfrentamento ${ }^{17}$.

De acordo com o Quadro 1, nos estudos em que o principal meio de educar o público foi mediante a distribuição de panfletos educativos, não houve resultados significativos em relação ao grupo que não houve nenhuma intervenção. Estratégias que utilizam apenas distribuição de materiais informativos são demasiadamente passivas para motivar o público a prevenir as arboviroses. Meios passivos e tradicionais de ensino, considerados por muito tempo padrão ouro dos programas de controle do mosquito, já não são mais suficientes para motivar a população a eliminar os locais de reprodução do vetor ${ }^{15}$.

Em uma revisão integrativa também foi evidenciado que muitas ações educativas ainda são desenvolvidas mediante palestras ministradas por profissionais de nível superior, criando uma educação verticalizada e pouco atrativa. Nestas estratégias há limitações e pontos a serem melhorados para garantir uma educação em saúde de qualidade. Entre os fatores relacionados à falta de participação popular, cita-se a resistência da população em aderir às campanhas, juntamente com a banalização do tema, que faz com que as doenças sejam vistas como algo do cotidiano e não como um problema de saúde pública ${ }^{12}$.

A hipótese que a educação ativa pode ser capaz de reduzir a fonte dos vetores e promover um melhor comportamento na comunidade foi confirmada, ao encontrar diferenças significativas na análise de medidas repetidas de comunidades em que houve educação ativa, em comparação ao grupo controle que se adotou o modo de ensino passivo $^{24}$.

No que se refere às características dos materiais educativos, foi possível perceber que aqueles com variedades de cores são mais eficazes na transmissão da mensagem, em contrapartida daqueles contendo cores em preto e branco, os quais apresentaram resultados semelhantes ao fornecimento de nenhum material. Logo, a elaboração de materiais educativos impressos requer conhecimentos de linguagem, designer e layout de materiais educativos, para torná-los o mais atrativo possível e de fácil compreensão ${ }^{15}$.

Além das residências, escolas e demais ambientes públicos também foram escolhidos para as intervenções educativas. Este achado demonstra um grande avanço em torno das ações de combate vetoriais, tendo em vista que elas não estiveram restritas apenas às residências, como observado há algum tempo atrás ${ }^{18}$. A ampliação das abordagens de enfrentamento às arboviroses em diferentes espaços públicos se justifica pelo fato dos vetores se reproduzirem, com mais frequência, também nas repartições públicas ${ }^{24}$.

Grande parte dos estudos, encontrados na revisão, optou por incluir escolas como locais de intervenções, por percebê-la como espaço adequado para formação cidadã. Os custos associados às campanhas em escolas são baixos $\mathrm{e}$ os resultados promissores. É possível aumentar o conhecimento, melhorar atitudes e práticas dos escolares para autogestão, contribuindo para que os educandos possam ser capazes de atuar como promotores da mudança de atitude no combate às doenças transmitidas pelo mosquito ${ }^{18,20}$. A variedade dos perfis de idade, gênero, escolaridade e profissões dos participantes dos estudos, demonstra a importância de abordagem a toda 
população e o quanto cada público, de acordo com as suas especificidades, é responsável pelo combate e redução das doenças transmitidas pelo Aedes, nos diferentes contextos, escolas, ruas, domicílios e locais de trabalho.

Entre os profissionais que demandam formação continuada em torno da temática, os Agentes de Endemias são prioritários. É importante que eles sejam capacitados, atualizando os conhecimentos e aperfeiçoando suas práticas, porque atuam diretamente no combate ao vetor e mantêm uma comunicação direta com a população. Fatores como o elevado tempo de profissão e a falta de incentivo profissional demandam que os gestores propiciem condições de reciclagem periodicamente ${ }^{17}$.

A partir da análise dos estudos incluídos na Categoria 2, observa-se que as estratégias de enfrentamento aos vetores têm sido gradativamente implementadas de modo articulado, tendo em vista além das capacitações, o desenvolvimento de atividades que envolvem a participação social mediante mutirões para limpeza e recolhimento de material reciclável. Tais atividades permitem a participação ativa da população e a torna partícipe do controle dos vetores. Este modelo de atenção vai de encontro com a proposta do Programa Nacional de Controle da Dengue (PNCD) ${ }^{10}$.

A participação social desencadeia uma quebra de relação autoritária entre os serviços de assistência e vigilância à saúde, o que reforça a necessidade de refletir sobre a participação popular nas ações de saúde e sobre a incorporação nas diretrizes governamentais de ações que visem à promoção da participação da comunidade no controle de endemias ${ }^{23}$. Segundo alguns pesquisadores, as estratégias que demonstraram resultados eficazes para melhorar conhecimentos, práticas e apropriação ou Empowerment (Empoderamento) da prevenção e controle das doenças vetoriais foram aquelas que envolveram mobilização social ${ }^{16}$.

Os resultados também apontaram para a necessidade de capacitação dos demais profissionais responsáveis pela manutenção dos ambientes públicos. Manter estes profissionais capacitados se torna indispensável, uma vez que eles, geralmente, demonstram alto nível de confiança e possuem pouca escolaridade, o que pode interferir de forma negativa no controle do mosquito ${ }^{18}$.

Comunidades que possuem historicamente um contexto sociocultural de organização comunitária têm uma capacidade maior de lidar com este tipo de problemática. Por outro lado, baixo nível de liderança implica na dinâmica da comu- nidade, fazendo com que a população tenha dificuldade para resolver problemas coletivos. Foi possível observar, nos bairros que as pessoas demonstraram iniciativa, organização social, participação, compromisso e capacidade de liderança, que as estratégias de prevenção das arboviroses obtiveram êxito ${ }^{22}$.

O estudo incluído na Categoria 3 aponta para a importância das ações educativas mesmo quando se dispõem de métodos de controle biológico, como algumas espécies de peixes e outros mariscos. O controle biológico com predadores das larvas do vetor em locais de armazenamento de água é outra estratégia alternativa adotada por muitos gestores públicos. Contudo, o controle biológico, sem a implementação de estratégias educativas, não demonstrou ser suficiente para redução das larvas ${ }^{26,27}$.

A estratégia de utilização de peixes em reservatórios de água é bastante disseminada no Brasil, algumas espécies de peixe são utilizadas para tal prática, entre elas: Betta splendens, Trichogaster trichopterus, Xiphophorus maculatus e Poecilia reticulata. Todos são eficazes na eliminação de larvas do mosquito, no entanto quando colocados em ambiente que apresentam além da existência de larvas uma quantidade maior de outros substratos que os peixes se alimentam, eles optam por se alimentar destes, ao invés das larvas do Aedes ${ }^{29}$.

Segundo as pesquisas, programas estruturados verticalmente nacionais, estaduais e de órgãos administrativos locais de controle de larvas, que não contaram com nenhum envolvimento da comunidade, conduzidas de forma isolada e irregular já demonstraram tender ao insucesso ${ }^{21}$. Além da utilização dos predadores naturais, é indispensável orientar a população quanto aos cuidados mínimos a respeito da forma adequada de armazenamento da água e quais alimentos alternativos para estes predadores, na ausência de $\operatorname{larvas}^{26,27}$.

A Categoria 4 foi composta por um estudo contendo o maior grau de articulação das ações de enfrentamento às arboviroses. As estratégias educativas já demonstraram grande potencial, contudo elas isoladamente se tornam insuficientes para a prevenção deste problema de saúde pública, há outros fatores que são indispensáveis, como a oferta de qualidade dos serviços públicos de saúde, infraestrutura, segurança e $\operatorname{lazer}^{28}$. A utilização isolada, seja ela de educação em saúde, controle biológico, inseticidas, dentre outras, não demonstraram efetividade e eficácia, sendo fundamental a associação de múltiplas estratégias e o envolvimento da gestão pública nesse contexto ${ }^{30}$. 
Todos os serviços essenciais devem ser estabelecidos como prioridades por parte dos gestores públicos em quaisquer comunidades, demandando investimentos que possam revitalizar bairros, melhorar as condições de saneamento básico, construção de estradas, calçadas, parques, disponibilização de serviços de segurança, coleta de lixo, melhorias para residências, uso de diferentes mídias, para informar acerca da importância de zelar pela manutenção de um ambiente isento de riscos à saúde ${ }^{30}$.

Torna-se urgente a mudança de paradigma de abordagens verticais para horizontais, a incorporação e fortalecimento de uma vigilância epidemiológica e entomológica ${ }^{28}$. As arboviroses precisam ser entendidas como problema de todos, cuja solução está na união de estados, serviços, profissionais e população. Assim, a responsabilidade deve ser compartilhada e as soluções devem ser criadas a partir do trabalho conjunto entre governo e sociedade. O caráter sazonal das campanhas deve ser substituído por uma educação permanente, que valorize o conhecimento popular, e que promova intervenções considerando a realidade social e cultural das pessoas. O processo educativo deve acontecer de maneira horizontal ${ }^{12}$.

Embora a "guerra contra o mosquito" seja necessária como providência imediata, ela não pode esconder que a lista de adversários da saúde é bem mais longa. Impõe-se a suspensão imediata de cortes orçamentários na área social, com a priorização de investimentos em saneamento básico e no fortalecimento dos Sistema Único de Saúde (SUS). Só um sistema de saúde eficiente pode garantir a continuidade da assistência às pessoas. Ademais, urge a implementação de uma agenda científica, com grande investimento em pesquisa que possam melhor avaliar as eficácias e os custos-benefícios das intervenções implementadas nos diferentes contextos ${ }^{30}$.

\section{Considerações finais}

Infere-se que a educação em saúde é um elemento indispensável para o enfrentamento às arboviroses que deverá ser implementada de forma conjunta e articuladas às demais estratégia de combate vetorial. As ações educativas de combate ao Aedes aegypti contribuem para melhoria do conhecimento e mudança de comportamento das comunidades, sensibilizando a população a gerenciar os ambientes que habitam.

Estiveram associados à utilização de estratégias educativas resultados positivos como: redução dos habitats do mosquito; eliminação de criadouros; diminuição de infestação vetorial; ampliação dos conhecimentos, atitudes e práticas em torno do controle vetorial que contribuíram para o tornar comunidades empoderadas.

Intervenções educativas em torno das doenças transmitidas pelo Aedes aegypti são ações estratégicas que devem ser implementadas de forma participativa e contínua, com métodos ativos, os quais demonstraram resultados mais satisfatórios na promoção à saúde, em contrapartida aos modelos de ensino verticalizados que demonstraram limitações para motivar a população para o controle de vetores.

A partir dos resultados desta revisão integrativa, recomenda-se que os gestores e representantes da sociedade civil dialoguem frequentemente com todos os seguimentos da comunidade para identificar quais fatores são preponderantes para o controle vetorial, uma vez que cada comunidade possui suas particularidades. Devem representar prioridades para um ambiente isento de doenças vetoriais, mobilizações coletivas, investimentos em saúde, segurança, lazer, infraestrutura, principalmente saneamento básico. 


\section{Colaboradores}

Todos os autores participaram da concepção do projeto, análise dos dados obtidos, redação e revisão final do artigo.

\section{Referências}

1. Lopes N, Linhares REC, Nozawa C. Características gerais e epidemiologia dos arbovírus emergentes no Brasil. Rev Pan-Amaz Saude 2014; 5(3):55-64.

2. Lima-Camara TN. Arboviroses emergentes e novos desafios para a saúde pública no Brasil. Rev Saude Publica 2016; 50:36.

3. Boeuf P, Drummer HE, Richards JS, Scoullar MJL, Beeson JG. The global threat of Zika virus to pregnancy: epidemiology, clinical perspectives, mechanisms, and impact. BMC Medicine 2016; 14:112.

4. Fauci AS, Morens DM. Zika Virus in the Americas — Yet Another Arbovirus Threat. N Engl J Med 2016; 374:601-604.

5. Carvalho NS, Carvalho BF, Dóris B, Biscaia ES, Fugaça CA, Noronha L. Zika virus and pregnancy: An overview. Am J Reprod Immunol 2017; 77:e12616.

6. Al-Muhandis N, Hunter PR. The Value of Educational Messages Embedded in a Community-Based Approach to Combat Dengue Fever: A Systematic Review and Meta Regression Analysis. PLoS Negl Trop Dis 2011; 5:e1278.

7. Luz PM, Vanni T, Medlock J, Paltiel AD, Galvani AP. Dengue vector control strategies in an urban setting: an economic modelling assessment. Lancet 2011; 377(9778):1673-1680.

8. Seley CM, González LJ, Tornese ML, Marchesi Olid LS, Martínez FN, Rossi ML, Troncoso A. Dengue and dengue haemorrhagic fever: its history and resurgence as a global public health problem: progress and challenges. Prensa Med Argent 2009; 96(7):395406.

9. Batista G, Thomé RCA, Pastore DH, Arruda EF, Dias CM, Yang HM. Modelagem do Aedes aegypti utilizando a bactéria Wolbachia como agente de controle. XLIX Simpósio Brasileiro de Pesquisa Operacional; 2017 ago 27-30; Blumenau-SC, Brasil.

10. Brasil. Ministério da Saúde (MS). Fundação Nacional de Saúde (Funasa). Dengue: aspectos epidemiológicos, diagnóstico e tratamento. Brasília: Funasa; 2002.

11. Ioosa S, Mallet HP, Goffart IL, Gauthier V, Cardoso T, Herida M. Current Zika virus epidemiology and recent epidemics. Med Maladies Infect 2014; 44:302307.

12. Silva VB, Mallmann DG, Vasconcelos EMR. Estratégias de combate à dengue através da educação em saúde: uma revisão integrativa. Saude (Santa Maria) 2015; 41(2):27-34.

13. Mendes KDS, Silveira RCCP, Galvão CM. Revisão integrativa: método de pesquisa para a incorporação de evidências na saúde e na enfermagem. Texto Contexto Enferm 2008; 17(4):758-764.

14. Galvão TF, Pansani TSA, Harrad D. Principais itens para relatar Revisões sistemáticas e Meta-análises: A recomendação PRISMA. Epidemiol Serv Saude 2015; 24(2):335-342.

15. Bartlett-Healy K, Hamilton G, Healy S, Crepeau T, Unlu I, Farajollahi A. Fonseca D, Gaugler R, Clark GG, Strickman D. Source reduction behavior as an independent measurement of the impact of a public health education campaign in an integrated vector management program for the Asian tiger mosquito. Int J Environ Res Public Health 2011; 8:1358-1367. 
16. Cáceres-Manrique FM, Angulo-Silva MP, Vesga-Gómez C. Eficacia de la movilización y la participación social para la apropiación o "empoderamiento" (sic.) (empowerment) de las medidas de control del dengue, Comuna Norte, Bucaramanga, 2008-2009. Biomedica 2010; 30:539-550.

17. Contreras NH, Oliva JN, Francisco NC, Valdés LS, Álvarez HH, Cantelar NC. Impacto de una intervención educativa en trabajadores de la campaña antivectorial. Rev Cub Med Trop 2012; 64(3):304-314.

18. Hernández-Suárez CM, Mendoza-Cano O. Empirical evidence of the effect of school gathering on the dynamics of dengue epidemics. Glob Health Action 2016; 9:28026.

19. Silva PC, Martins AM, Schall VT. Cooperação entre agentes de endemias e escolas na identificação e controle da dengue. Rev Bras Promoc Saude 2013; 26(3):404-411.

20. Torres JL, Ordóñez JG, Vázquez-Martínez MG. Conocimientos, actitudes y prácticas sobre el dengue en las escuelas primarias de Tapachula, Chiapas, México. Rev Panam Salud Publica 2014; 35(3):214218.

21. Arunachalam N, Tyagi BK, Samuel M, Krishnamoorthi R, Manavalan R, Tewari SC, Ashokkumar V, Kroeger A, Sommerfeld J, Petzold M. Community-based control of Aedes aegypti by adoption of eco-health methods in Chennai City, India. Pathogens Glob Health 2012; 106(8):488-496.

22. Caprara A, Lima JWO, Peixoto ACR, Motta CMV, Nobre JMS, Sommerfeld J, Kroeger A. Entomological impact and social participation in dengue control: a cluster randomized trial in Fortaleza, Brazil. Trans $R$ Soc Trop Med Hyg 2015; 109:99-105.

23. Costa MMC, Barbosa MJP, Freitas VC, Albuquerque PC. Amigos do bairro contra dengue: a experiência do distrito sanitário da III secretaria de saúde do Recife, implantação de um projeto de participação popular em saúde. Rev APS 2012; 15(4):517-521.

24. Healy K, Hamilton G, Crepeau T, Healy S, Unlu I, Farajollahi A, Fonseca D. Integrating the Public in Mosquito Management: Active Education by Community Peers Can Lead to Significant Reduction in Peridomestic Container Mosquito Habitats. PLoS One 2014; 9:e108504.
25. Kittayapong P, Thongyuan S, Olanratmanee P, Aumchareoun W, Koyadun S, Kittayapong R, Butraporn P. Application of eco-friendly tools and eco-biosocial strategies to control dengue vectors in urban and peri-urban settings in Thailand. Pathogens Glob Health 2012; 106(8):446-454.

26. Mitchell-Foster K, Ayala EB, Breilh J, Spiegel J, Wilches AA, Leon TO, Delgado JA. Integrating participatory Community mobilization processes to improve dengue prevention: an eco-bio-social scaling up of local success in Machala, Ecuador. Trans $R$ Soc Trop Med Hyg 2015; 109:126-133.

27. Ghosh SK, Chakaravarthy P, Panch SR, Krishnappa P, Tiwari S, Ojha VP, ManjushreeR, Dash AP. Comparative efficacy of two poeciliid fish in indoor cement tanks against chikungunya vector Aedes aegypti in villages in Karnataka, India. BMC Public Health 2011; 11:599.

28. Nam VS, Yen NT, Duc HM, Tu TC, Thang VT, Le NH, San LH, Loan LL, Huong VTQ, Khanh LHK, Trang HTT, Lam LZY, Kutcher SC, Aaskov JG, Jeffery JAL, Ryan PA, Kay BH. Community-Based Control of Aedes aegypti By Using Mesocyclops in Southern Vietnam. Am J Trop Med Hyg 2012; 86(5):850-859.

29. Paiva CN, Lima JW, Camelo SS, Lima CF, Cavalcanti LP. Survival of larvivorous fish used for biological control of Aedes aegypti (Diptera: Culicidae) combined with different larvicides. Trop Med Int Health 2014; 19(9):1082-1086.

30. Possas C. Zika: what we do and do not know based on the experiences of Brazil. Epidemiol Health 2016; 38:e2016023.

Artigo apresentado em 22/06/2018

Aprovado em 06/11/2020

Versão final apresentada em 08/11/2020

Editores-chefes: Romeu Gomes, Antônio Augusto Moura da Silva 